\title{
Effects of oestrogens and anti-oestrogens on normal breast tissue from women bearing BRCAI and BRCA2 mutations
}

\author{
M Bramley ${ }^{1,2,5}$, RB Clarke ${ }^{*, 2,5}$, A Howell ${ }^{3}$, DGR Evans ${ }^{4}$, T Armer², AD Baildam' and E Anderson ${ }^{2,6}$ \\ 'Department of Surgery, Christie Hospital NHS Trust, Manchester M20 4BX, USA; ${ }^{2}$ Clinical Research Department, Christie Hospital NHS Trust, \\ Manchester M20 4BX, USA; ${ }^{3}$ CR-UK Department of Medical Oncology, Christie Hospital NHS Trust, Manchester M20 4BX, USA; ${ }^{4}$ University \\ Department of Medical Genetics and Regional Genetics Service, St Mary's Hospital, Manchester MI 3 OJH, USA
}

There is considerable interest in whether anti-oestrogens can be used to prevent breast cancer in women bearing mutations in the $B R C A$ I and BRCA2 genes. The effects of oestradiol $\left(E_{2}\right)$, tamoxifen (TAM) and fulvestrant (FUL) on proliferation and steroid receptor expression were assessed in normal breast epithelium taken from women at varying risks of breast cancer and implanted into athymic nude mice, which were treated with $E_{2}$ in the presence and absence of TAM or FUL. Tissue samples were taken at various time points thereafter for assessment of proliferative activity and expression of oestrogen and progesterone receptors (ER $\alpha$ and PgR) by immunohistochemistry. Oestradiol increased proliferation in the breast epithelium from women carrying mutations in the BRCA //2 genes, those otherwise at increased risk and those at population risk of breast cancer. This increase was reduced by both TAM and FUL in all risk groups. In the absence of $E_{2}$, PgR expression was reduced in all risk groups but significantly more so in the BRCAmutated groups. Subsequent $E_{2}$ treatment caused a rapid, complete induction of PgR expression in the population-risk group but not in the high-risk or BRCA-mutated groups in which PgR induction was significantly delayed. These data suggest that the mechanisms by which $E_{2}$ induces breast epithelial PgR expression are impaired in BRCA //2 mutation carriers, whereas those regulating proliferation remain intact. We conclude that early anti-oestrogen treatment should prevent breast cancer in very high-risk women.

British Journal of Cancer (2006) 94, 1021 - 1028. doi:I0.1038/sj.bjc.6603042 www.bjcancer.com

Published online 14 March 2006

(c) 2006 Cancer Research UK

Keywords: breast epithelium; oestradiol; tamoxifen; fulvestrant; proliferation; steroid receptors

Approximately $5 \%$ of all cases of breast cancer are associated with inherited predisposition syndromes and about half of these are attributable to mutations in the BRCA1 and BRCA2 genes (Hopper, 2001). Carriers of mutations in the $B R C A 1$ and $B R C A 2$ genes have up to a $90 \%$ lifetime risk of developing breast cancer (Rebbeck, 2002) and effective preventative strategies are required for these women.

A number of trials have now shown that endocrine agents such as tamoxifen (TAM) or raloxifene can prevent breast cancer in women at increased risk of the disease (Cuzick et al, 2003). The question arises as to whether agents such as these can be used for prevention specifically in women bearing BRCA1 or BRCA2 mutations. The prevalence of mutations in the total cohort in the NSABP P1 trial was unknown (Fisher et al, 1998) and therefore no conclusion regarding the effectiveness of TAM in mutation carriers can be made from this study. It has been suggested that endocrine

\footnotetext{
*Correspondence: Dr RB Clarke, Breast Biology Group, University of Manchester, Christie Hospital NHS Trust, Wilmslow Road, Manchester M20 4BX, UK; E-mail: rclarke@picr.man.ac.uk

${ }^{5}$ These authors contributed equally to this work

${ }^{6}$ Current address: Cancer and Infection Bioscience, AstraZeneca, Mereside, Alderley Park, Macclesfield, Cheshire SKIO 4TG, USA Received 27 October 2005; revised 8 February 2006; accepted 8 February 2006; published online 14 March 2006
}

agents such as TAM will not be effective in preventing breast cancer in BRCA1 mutation carriers because the majority of tumours (up to $80 \%$ ) arising in these women are oestrogen receptor $\alpha(\operatorname{ER} \alpha)$ negative, have a high mitotic rate and are of high histological grade (Lakhani, 1999; Lakhani et al, 2002). All these features are associated with resistance to endocrine therapy and it is clear from the overview that TAM and raloxifene reduce the incidence of ER $\alpha$-positive but not -negative tumours (Cuzick et al, 2003). Against these, however, are data showing that incidence of breast cancer in BRCA1 and BRCA2 mutation carriers is altered by endocrine risk modifiers such as pregnancy (Rebbeck et al, 2001). Moreover, it is becoming clear that prophylactic oophorectomy not only reduces the incidence of ovarian cancer in mutation carriers but also that of breast cancer (Rebbeck et al, 2002). Finally, it has been shown that both oophorectomy and adjuvant TAM treatment reduce the risk of contralateral breast cancer in mutation carriers (Narod et al, 2000; Metcalfe et al, 2004). This raises the possibility that the initial stages of tumour formation in $B R C A 1$ and BRCA2 mutation carriers are hormone dependent, in which case early endocrine therapy might be an effective prevention strategy. This possibility is not addressed by existing trials such as the one run by the NSABP because the effects of TAM became evident after a relatively short follow-up period, suggesting that the anti-oestrogen was preventing progression of existing subclinical lesions rather than inhibiting de novo tumorigenesis (Fisher et al, 1998). 
Significant advances have been made towards understanding the mechanisms by which BRCA1 and BRCA2 act. The products of both genes are large, ubiquitously expressed proteins that have fundamental roles in protecting and repairing the genome (Deng and Scott, 2000; Kerr and Ashworth, 2001; Venkitaraman, 2001). The prevailing view on the mechanism by which heterozygous mutations in the BRCA1 and BRCA2 genes predispose to cancer is that they provide an unstable genetic environment in which further mutations leading to tumorigenesis are more likely to occur (Deng and Scott, 2000). However, this does not explain why $B R C A 1$ or $B R C A 2$ mutations predispose so specifically to breast and ovarian cancer nor why $B R C A 1$ or $B R C A 2$ insufficiency can have profound effects on processes such as proliferation and differentiation. For example, global deletion of either gene in mice leads to embryonic lethality due to defects in proliferation and/or differentiation as well as genetic instability (Deng and Scott, 2000; Deng and Brodie, 2001). Conditional mutation of BRCA1 in the mammary epithelium results in abnormal gland formation and increased apoptosis (Xu et al, 1999; Brown et al, 2002). Both $B R C A 1$ and $B R C A 2$ are expressed in tissues undergoing rapid proliferation prior to undergoing terminal differentiation including the pregnant mammary gland (Chodosh, 1998). In addition, in vitro studies indicate that $B R C A 1$, in particular, interacts with and represses both nuclear and nongenomic ER $\alpha$ signalling pathways (Fan et al, 1999; Fan et al, 2001; Razandi et al, 2004). These data raise the possibility that proliferation and expression of oestrogenregulated genes are altered in oestrogen target tissues such as the mammary gland. The aims of the present study were two-fold: first, to determine whether $B R C A 1$ or $B R C A 2$ haploinsufficiency altered the oestrogen sensitivity of normal breast epithelium in terms of proliferation and induction of oestrogen-induced genes. The second aim was to find out whether tamoxifen, a selective oestrogen receptor modulator (SERM) and fulvestrant, an antioestrogen devoid of agonist activity, were able to abrogate the proliferative effects of $E_{2}$ on normal breast tissue from women carrying BRCA1 and BRCA2 mutations or who were, otherwise, at increased risk of developing breast cancer. To do this, we used a model of normal human breast tissue implanted into athymic nude mice where it was treated with oestradiol $\left(\mathrm{E}_{2}\right)$ and/or antioestrogens. We show that epithelial proliferation in breast tissue from women with $B R C A 1$ and $B R C A 2$ mutations or who are otherwise at high risk is stimulated by oestradiol to the same extent to that in tissue taken from women at population risk of breast cancer. The effects of $\mathrm{E}_{2}$ on proliferation could be reduced by the addition of TAM or fulvestrant in all three risk groups. However, induction of progesterone receptor expression by $E_{2}$ was impaired in the tissue taken from $B R C A 1$ and $B R C A 2$ carriers compared to that taken from women at population risk of breast cancer.

\section{MATERIALS AND METHODS}

\section{Subjects}

Breast tissue was obtained from women at the population risk of breast cancer $(n=22)$ at surgery for removal of a fibroadenoma as described previously (Laidlaw et al, 1995). 'Mutated' tissue was obtained at prophylactic mastectomy from women with documented linkage to or mutations in the BRCA1 $(n=5)$ or BRCA2 genes $(n=3)$. In the case of $B R C A 1$, one subject was shown to be a mutation carrier through linkage analysis, but was not sequenced, whereas the other four were characterised by direct sequencing which identified the following mutations: 185delAG, 1294del40, 502del5 and 2799delAA. The three subjects with BRCA2 mutations were related and direct sequencing confirmed that they had the same lesion, 6819delTG. 'Increased-risk' tissue was taken at either prophylactic mastectomy or biopsy in women judged to be at increased risk of breast cancer either by family history or a previous history of cancer $(n=18)$. Of these, 12 were undergoing bilateral prophylactic mastectomy because their family history indicated a lifetime risk of breast cancer greater than one in four, three were undergoing prophylactic removal of an uninvolved breast contralateral to one containing tumour and in three cases, tissue was obtained at biopsy from women with a more moderate family history calculated to put them at a lifetime risk of one in six or greater. The three groups (population risk, mutation carriers and high risk) of women were well matched for age at operation and for endocrine breast cancer risk factors such as age at menarche, parity and age at first full-term pregnancy (see Table 1). The study was approved by the Ethics Committee of the South Manchester Hospitals and all subjects gave informed consent for the use of their normal tissue in research studies. In all cases, the

Table I Characteristics of the subjects from whom tissue was taken for analysis of the effects of oestradiol and anti-oestrogens on proliferation and steroid receptor expression in normal breast epithelium

\begin{tabular}{|c|c|c|c|c|}
\hline & $\begin{array}{l}\text { Population } \\
\text { risk }\end{array}$ & Mutated & $\begin{array}{l}\text { High } \\
\text { risk }\end{array}$ & \\
\hline \multicolumn{5}{|c|}{ Age at operation (years) } \\
\hline \multicolumn{5}{|c|}{ All subjects } \\
\hline Median & 36.5 & 37 & 37.5 & $n s d^{2}$ \\
\hline Range & $16-46$ & $29-53$ & $24-54$ & \\
\hline$n$ & 22 & 8 & 18 & \\
\hline \multicolumn{5}{|c|}{ Subjects whose tissue was implanted } \\
\hline Median & 40 & 39 & 38.5 & nsd \\
\hline Range & $31.5-44$ & $29-53$ & $25-54$ & \\
\hline$n$ & 9 & 7 & 12 & \\
\hline \multicolumn{5}{|c|}{ Age at menarche (years) } \\
\hline \multicolumn{5}{|c|}{ All subjects } \\
\hline Median & 13 & 13 & 12.5 & nsd \\
\hline Range & $10.5-16$ & $11-15$ & $10-16$ & \\
\hline$n$ & 20 & 7 & 18 & \\
\hline \multicolumn{5}{|c|}{ Subjects whose tissue was implanted } \\
\hline Median & 12.25 & 13 & 12.5 & nsd \\
\hline Range & $11.5-16$ & $11-15$ & $11-15$ & \\
\hline$n$ & 9 & 6 & 12 & \\
\hline \multicolumn{5}{|l|}{ Parity } \\
\hline \multicolumn{5}{|l|}{ All subjects } \\
\hline Median & 2 & 2 & 2 & \\
\hline Range & $0-4$ & $0-3$ & $0-7$ & nsd \\
\hline n & 22 & 8 & 18 & \\
\hline \multicolumn{5}{|c|}{ Subjects whose tissue was implanted } \\
\hline Median & 2 & 2 & 3 & nsd \\
\hline Range & $0-4$ & $0-3$ & $0-7$ & \\
\hline n & 9 & 7 & 12 & \\
\hline \multicolumn{5}{|c|}{ Age at FFTP (years) } \\
\hline \multicolumn{5}{|c|}{ All subjects } \\
\hline Median & 22 & 25.5 & 21 & \\
\hline Range & $17-33$ & $19-35$ & $17-30$ & nsd \\
\hline$n$ & 17 & 6 & 15 & \\
\hline \multicolumn{5}{|c|}{ Subjects whose tissue was implanted } \\
\hline Median & 21.5 & 25.5 & 21 & nsd \\
\hline Range & $18-33$ & $19-35$ & $19-30$ & \\
\hline$n$ & 8 & 6 & | | & \\
\hline
\end{tabular}

Population risk $=$ women at population risk of breast cancer undergoing removal of a fibroadenoma; 'Mutated' $=$ women carrying mutations in the BRCAI and BRCA2 genes undergoing prophylactic mastectomy; High risk = women at very high risk of breast cancer due to family history also undergoing prophylactic mastectomy or biopsy in women judged to be at increased risk of breast cancer either by family history or a previous history of cancer. ${ }^{a}$ nsd = no significant difference between the risk groups by Kruskal-Wallis test. ${ }^{b}$ FFTP $=$ first full-term pregnancy. 
tissue used in the implantation studies was examined by an experienced histopathologist (Dr J Coyne) to confirm the presence of normal lobules only. Tissue samples from nine of the 22 population-risk subjects, seven of the eight samples of the 'mutated' tissue and 12 of the 18 'increased-risk' samples were used for the implantation studies.

\section{Implantation of breast tissue into athymic nude mice}

All the following procedures were carried out under the Animals (Scientific Procedures) Act of 1986 and complied with UKCCCR Guidelines regarding the ethical use of animals. Implantation of human breast tissue into athymic nude mice was performed as described previously (Laidlaw et al, 1995). Each sample of breast tissue was divided into small pieces $(2 \times 2 \times 1 \mathrm{~mm})$, eight of which were implanted subcutaneously (s.c.) into each of at least 16 intact female adult (9-10 weeks old) nu/nu, balb/c mice. At 2 weeks after tissue implantation, control silastic pellets were inserted s.c. into four of the mice, whereas two groups of six mice received 0.5 or $2.0 \mathrm{mg} \mathrm{E}$-silastic pellets prepared as described previously (Laidlaw et al, 1995). After 1 week, the two groups of $\mathrm{E}_{2}$-treated mice were subdivided such that two mice received injections of the partial agonist anti-oestrogen TAM ( $1 \mathrm{mg}$ mouse ${ }^{-1}$ day $^{-1}$ in peanut oil s.c.), two received the specific anti-oestrogen fulvestrant (ICI 182 780 ; $5 \mathrm{mg}$ mouse $^{-1}$ week $^{-1}$ s.c. in castor oil) and two the appropriate vehicle control (peanut or castor oil). These doses were chosen because they had been shown to inhibit the growth of MCF-7 human breast tumours in athymic nude mice (Osborne et al, 1995) and treatments were continued for 2 weeks. Two tissue samples were removed from each of the mice 2, 3, 4 and 5 weeks after implantation, fixed in $4 \%$ buffered formalin overnight at $4{ }^{\circ} \mathrm{C}$, then embedded in paraffin wax. Blood was taken from the mice at the conclusion of each experiment and serum $\mathrm{E}_{2}$ levels were assayed by RIA as described (Laidlaw et al, 1995). The median serum $\mathrm{E}_{2}$ concentration in the mice treated with control silastic pellets was $107 \mathrm{pM}$ with an interquartile (IQ) range of 74-214 pM $(n=100)$, those treated with $0.5 \mathrm{mg} \mathrm{E}_{2}$ pellets had a final median concentration of $386 \mathrm{pM}$ (IQ range $268-745 \mathrm{pM} ; n=59$ ), whereas those treated with $2 \mathrm{mg} \mathrm{E}_{2}$ pellets achieved a final median serum concentration of $1050 \mathrm{pM}$ (IQ range $785-1660 \mathrm{pM} ; n=57$ ).

\section{Immunohistochemical assessment of proliferation and steroid receptor expression}

Proliferative activity was assessed by immunohistochemistry (IHC) using the mouse monoclonal antibody MIB-1 (Coulter Ltd, UK) raised against the Ki67 proliferation-associated antigen. Expression of $\mathrm{ER} \alpha$ and PgR was determined by IHC using a mouse monoclonal anti-ER $\alpha$ antibody (clone ID5, Dako Ltd, UK) and a rat monoclonal anti-PR antibody (clone KD68, Abbott Laboratories, UK), respectively. Microwave antigen retrieval methods and dilutions were as described previously (Clarke et al, 1997a). Antibody binding was detected indirectly using the appropriate biotinylated second antibodies, a peroxidase-conjugated avidinbiotin complex (ABC Elite, Vector Laboratories, UK) and diaminobenzidine as the chromogen. Quantitation of immunostaining was carried out on a light microscope and was restricted to the epithelial cells of the terminal duct lobulo-alveolar units. Areas to be counted were selected out of focus at low power and then complete high-power fields were scored. At least 1000 epithelial cells were scored per sample and the number of labelled cells was expressed as a percentage of the total cells counted. The intensity of staining was not assessed.

\section{Statistical methods}

Throughout, the data are presented as medians together with their respective interquartile ranges (IQRs). Overall changes across treatment or risk groups were analysed using the Kruskal-Wallis nonparametric, one-way analysis of variance. If this proved significant at the $5 \%$ level, then pairwise comparisons were made using the nonparametric Mann-Whitney $U$-test.

\section{RESULTS}

\section{Oestradiol stimulates breast epithelial cell proliferative activity in all risk groups}

Analysis of the tissue samples, fixed at the time of removal from the patients, revealed no differences in the percentages of breast epithelial cells labelled with the anti-Ki67 antibody between the different risk groups (see Table 2). At 2 weeks after implantation into the mice and before treatment commenced, epithelial Ki67 expression decreased to approximately $1 \%$ and, again, there were no significant differences between the samples taken from the different risk groups (see Table 3 and Figure 1). Figure 1 shows the proliferative activity of the tissue samples from the different risk groups taken before (day 0) and 1 week (day 7) after the start of $E_{2}$ or control treatment. In the absence of $\mathrm{E}_{2}$, epithelial Ki67 expression in the tissue samples from the population- and high-risk tissue groups remained at the levels seen before treatment (Figure $1 \mathrm{~A}$ and $\mathrm{B}$ ). The median Ki67LI in the tissue samples from the 'All mutations' group (Figure 1C) decreased although not significantly so. However, separate analysis of the samples from women bearing BRCA1 mutations (Figure 1D) indicated that, in the absence of $\mathrm{E}_{2}$, the epithelial Ki67LI decreased significantly to a median of $0.7 \%$ (IQR $=0.4-1.0 ; n=21 ; P=0.009$ by Mann - Whitney $U$-test). The reasons for this decline in proliferative activity in the tissue taken from women carrying BRCA1 mutations compared to that from women at population risk are not clear at present, but it may be due simply to the variability in the data from the latter group. Figure 1 also shows the breast epithelial Ki67LIs in each of the risk groups after 1 week's treatment with 0.5 and $2 \mathrm{mg} \mathrm{E}_{2}$. In the population-risk group, there was an increase in the Ki67LI after treatment with the $0.5 \mathrm{mg} \mathrm{E}_{2}$ pellet although this was not statistically significant. In the other three risk groups, the Ki67LI increased significantly after treatment with the low-dose $\mathrm{E}_{2}$ pellet $(P<0.001$ by Mann-Whitney $U$-test $)$

Table 2 Proliferation (Ki67), oestrogen receptor alpha (ER $\alpha$ ) and progesterone receptor (PgR) expression in samples of breast epithelium taken from women at population risk of breast cancer undergoing removal of a fibroadenoma, from BRCAI or BRCA2 mutation carriers undergoing prophylactic mastectomy ('mutated') or from women at high risk of breast cancer also undergoing prophylactic mastectomy or biopsy in women judged to be at increased risk of breast cancer either by family history or a previous history of cancer

\begin{tabular}{lccccc}
\hline & $\begin{array}{c}\text { Population } \\
\text { risk }\end{array}$ & $\begin{array}{c}\text { High } \\
\text { risk }\end{array}$ & BRCA I+BRCA2 & $\begin{array}{c}\text { BRCAI } \\
\text { only }\end{array}$ & \\
\hline$n$ & 22 & 18 & 8 & 5 & \\
Ki67 (\%) & 2.3 & 1.5 & 2.9 & 2.9 & nsd $^{b}$ \\
$\quad$ Median & $1.3-8.2$ & $1.1-3.5$ & $0.9-4.0$ & $0.7-4.8$ & \\
$\quad$ IQ range & 1.3 & & & \\
$\begin{array}{c}\text { ER (\%) } \\
\quad \text { Median }\end{array}$ & 27.9 & 21.6 & 29.6 & 27.3 & nsd \\
$\begin{array}{l}\text { IQ range } \\
\text { PgR (\%) }\end{array}$ & $16.9-32.9$ & $17.3-35.8$ & $12.2-35.2$ & $13.2-36.0$ & \\
$\quad$ Median & 24.8 & 20.6 & 19.5 & 15.3 & nsd \\
IQ range & $16.3-35.6$ & $15.9-26.4$ & $9.4-28.8$ & $4.8-24.7$ & \\
\hline
\end{tabular}

The figures represent the proportion of positively stained epithelial cells expressed as a percentage of the total number of cells counted. ${ }^{\mathrm{a}} \mathrm{Q}$ range - interquartile range. ${ }^{b}$ nsd $=$ no significant difference between the three risk groups by Kruskal-Wallis test. 

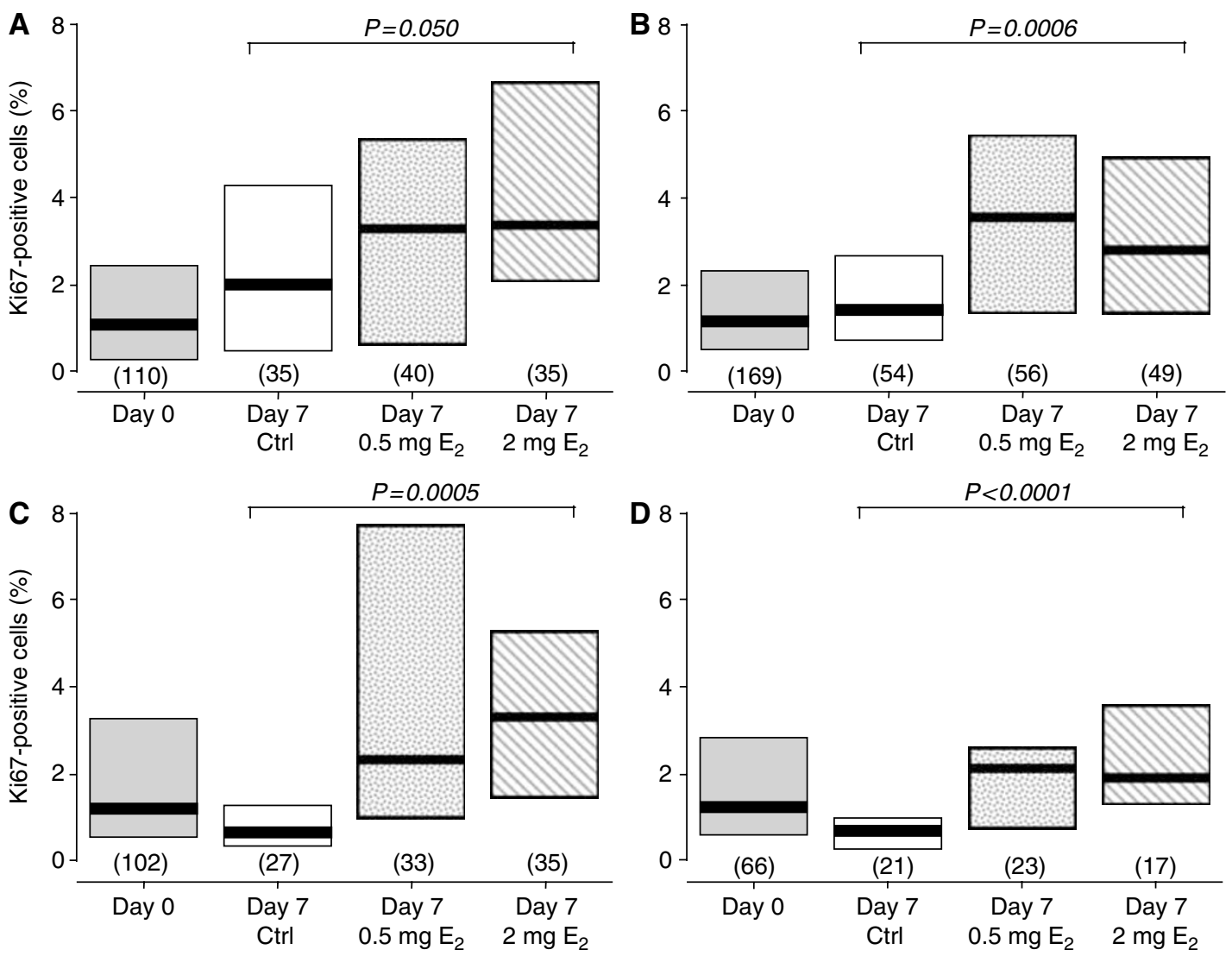

Treatment

Figure I Proliferative activity of normal breast epithelium taken from women at population risk of breast cancer $(\mathbf{A})$, those at high risk (B) All BRCA I or BRCA2 mutation carriers $(\mathbf{C})$ and BRCA I mutation carriers only $(\mathbf{D})$, which had been implanted into athymic nude mice before (day 0 ) and after I week's treatment with control, $0.5 \mathrm{mg} \mathrm{E}_{2}$ or $2.0 \mathrm{mg} \mathrm{E}_{2}$-silastic pellets. The thick horizontal lines indicate the median values as do the figures above the columns indicating the IQRs. The numbers in parentheses are the numbers of samples available for analysis in each group and the $P$-values indicate the significance of the differences across the treatment groups by Kruskal-Wallis nonparametric analysis of variance. Ctrl = control.

Table 3 Proliferation (Ki67) and progesterone receptor (PgR) expression in samples of human breast epithelium 14 days after being implanted into the athymic nude mice and before the initiation of treatment

\begin{tabular}{lccccc}
\hline & $\begin{array}{c}\text { Population } \\
\text { risk }\end{array}$ & $\begin{array}{c}\text { High } \\
\text { risk }\end{array}$ & BRCAI + BRCA2 & $\begin{array}{c}\text { BRCAI } \\
\text { only }\end{array}$ & \\
\hline Ki67 (\%) & & & & & \\
Median & 1.08 & 1.16 & 1.21 & 1.25 & $\mathrm{nsd}^{\mathrm{a}}$ \\
IQ range & $0.3-2.45$ & $0.50-2.30$ & $0.57-3.28$ & $0.61-2.84$ & \\
$n^{c}$ & 110 & 169 & 102 & 66 & \\
PgR (\%) & & & & & \\
Median & 9.60 & 9.12 & 2.94 & 1.99 & $P<0.00 I^{a}$ \\
IQ range & $5.34-18.48$ & $4.32-15.30$ & $0.96-8.51$ & $0.90-5.04$ & \\
$n$ & 63 & 101 & 86 & 52 & \\
\hline
\end{tabular}

The figures represent positively stained epithelial cells expressed as a percentage of the total number of cells counted. ${ }^{a}$ Significance of comparison between risk groups by Kruskal - Wallis test; $\mathrm{nsd}=$ no significant difference. ${ }^{\mathrm{b}} \mathrm{QQ}$ range $=$ inter-quartile range. ${ }^{c} n=$ number of tissue samples in which parameter could be measured.

compared to the appropriate untreated control. Treatment with the high-dose ( $2 \mathrm{mg}) \mathrm{E}_{2}$ pellet (Figure 1C) significantly increased the median Ki67LIs in all four of the risk groups $(P<0.001$ by Mann-Whitney $U$-test) when compared to the corresponding control values.

\section{Induction of progesterone receptor expression by oestradiol is impaired in breast tissue from $B R C A$ mutation carriers}

There were no significant differences in the levels of breast epithelial cell $\mathrm{ER} \alpha$ and PgR expression between the risk groups at the time tissue was removed from the women (Table 2). However, 14 days after implantation into untreated mice, there was a significant decrease in the percentage of PgR-positive cells in all risk groups (Table 3 ). This was most pronounced in the tissue samples from women bearing BRCA1 mutations and resulted in the percentage of PgR-positive cells being approximately four-fold lower than that of the population-risk group $(P<0.001$ by MannWhitney $U$-test). Figure 2 shows the effects of 1 week's treatment with control, low- and high-dose $\mathrm{E}_{2}$-silastic pellets on $\mathrm{PgR}$ expression in breast epithelial cells. Levels of PgR expression were not altered in the control-treated samples (Figure 2A), and the differences between the risk groups were maintained. Figure 2B shows that treatment with the low-dose $E_{2}$ pellet increased epithelial cell PgR expression in samples from all the risk groups. However, the responses to low-dose $\mathrm{E}_{2}$ in the All mutations and $B R C A 1$ groups were attenuated such that the percentages of PgRpositive epithelial cells were increased only to $9.6 \%$ (IQR $=4.9$ $21.3)$ and $6.8 \%(\mathrm{IQR}=2.1-20.4)$, respectively. These increases in PgR expression in the samples from the All mutations and $B R C A 1$ groups almost, but not quite, reached statistical significance when compared to the corresponding control-treated samples $(P=0.051$ 


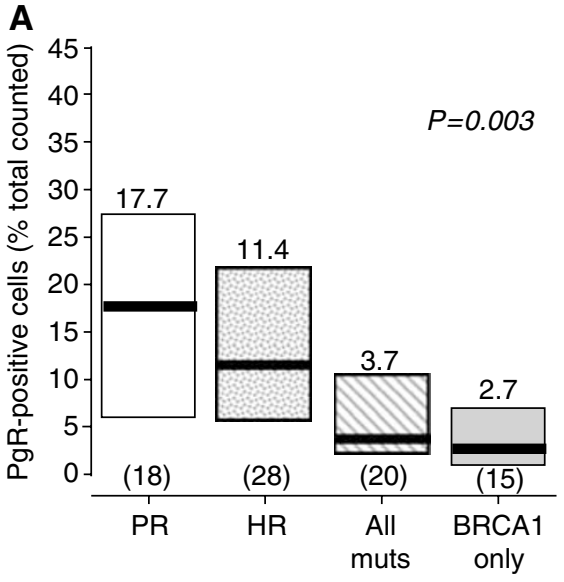

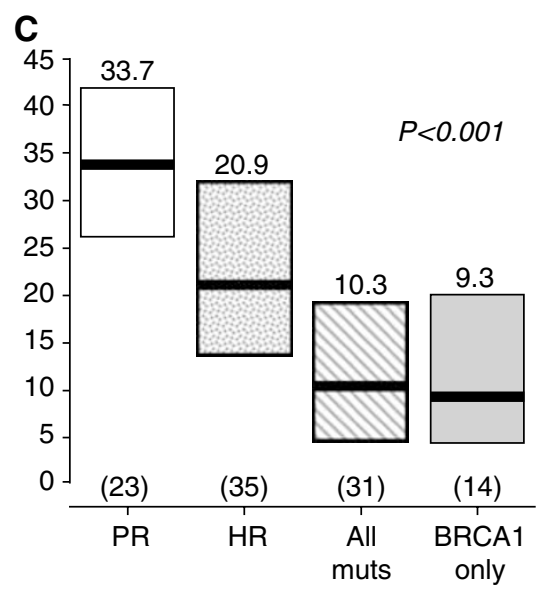

Figure 2 Progesterone receptor expression in normal breast epithelium taken from women at population risk of breast cancer, those at high risk and those carrying BRCAI and BRCA2 mutations, which had been implanted into athymic nude mice and treated for I week with control, (A), 0.5 mg $E_{2}$ (B) or $2.0 \mathrm{mg} \mathrm{E} \mathrm{E}_{2}(\mathbf{C})$-silastic pellets. The thick horizontal lines indicate the median values as do the figures above the columns indicating the IQRs. The numbers in parentheses are the numbers of samples available for analysis in each group and the $P$-values indicate the significance of the differences across the risk groups by Kruskal-Wallis nonparametric analysis of variance. $\mathrm{PgR}=$ progesterone receptor; $\mathrm{PR}=$ population risk; $\mathrm{HR}=$ high risk; All muts = all mutations; $\mathrm{BRCA}$ only $=$ BRCA I mutation carriers only.

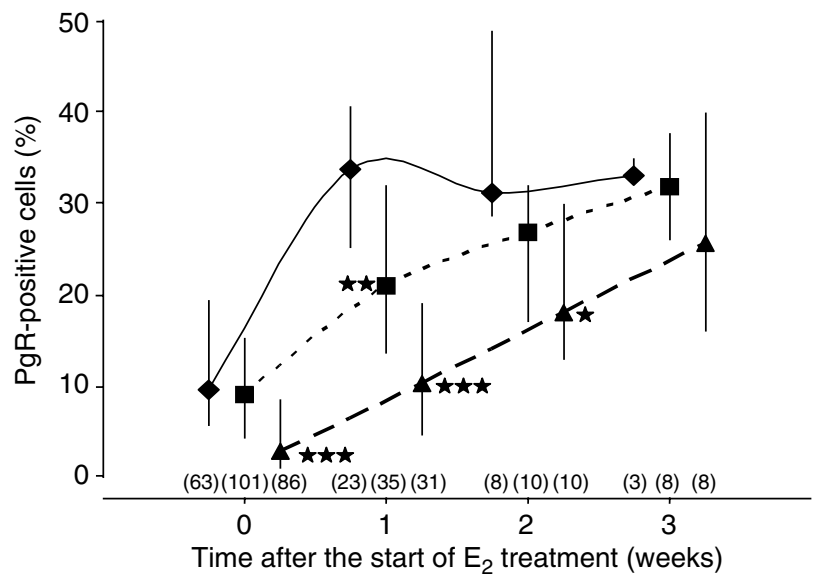

Figure 3 The effects of $E_{2}$ treatment over time on progesterone receptor expression in breast epithelium from women at population risk of breast cancer ( $)$ compared to that from women at high risk $(\mathbf{\square})$ and those carrying BRCAI and BRCA2 mutations $(\boldsymbol{\Delta})$. The median values are represented by the solid symbols, whereas the error bars indicate the IQRs and the numbers in parentheses are the samples available for analysis in each group. $* P<0.05$, ** $P<0.01$ and $* * * P<0.001$ compared to the population risk group by Mann-Whitney $U$-test. $\mathrm{PgR}=$ progesterone receptor.

and 0.07 , respectively, by Mann-Whitney $U$-test). Expression of the PgR in breast epithelium from all the risk groups was also induced by 1 week's treatment with high-dose $E_{2}$ (Figure 2C). However, the increase in the samples from the high-risk group did not reach the same level as that in the population-risk samples ( $P=0.002$ by Mann-Whitney $U$-test). The responses in the All Mutations and BRCA1 groups were diminished considerably in that they reached medians of only $10.3 \%(\mathrm{IQR}=4.6-19.2)$ and $9.3 \% \quad(\mathrm{IQR}=4.4-20.0)$, respectively $(P=0.062$ and 0.012 vs corresponding control-treated samples by Mann - Whitney $U$-test).

The effects of the high-dose $\mathrm{E}_{2}$ pellet on $\mathrm{PgR}$ expression in human breast epithelium at all time points after the start of treatment are shown in Figure 3. In the tissue samples from the population-risk group, PgR expression was maximal after 1 week of treatment with the high-dose $\mathrm{E}_{2}$ pellet and this level was maintained for the remainder of the experimental period. In contrast, the response in the All mutations group was attenuated such that percentages of PgR-positive cells in samples from this group were significantly lower than those of the population-risk group not only before the start of treatment but also for 2 weeks afterwards $(P<0.001$ by Mann-Whitney $U$-test at each time point). By the final time point, the median percentage of PgRpositive cells in samples from the All Mutations group had increased such that it approximated to that of the population-risk group. The effects of $E_{2}$ on PgR expression in tissue samples from the BRCA1 group could not be examined separately due to the small number of tissue samples available for analysis at the later time points. Examination of the effects of $E_{2}$ on PgR expression in the tissue samples from the high-risk group of women confirmed the results shown above in that the percentage of PgR-positive epithelial cells in this group after 1 week of high-dose $\mathrm{E}_{2}$ treatment was significantly lower than that of the population-risk group but thereafter, there were no significant differences between the two groups.

\section{Tamoxifen and fulvestrant reverse the effects of $E_{2}$ on breast epithelial cell proliferative activity in all risk groups}

Figure 4 shows Ki67 expression in normal breast tissue samples taken from the mice after treatment with $0.5 \mathrm{mg} \mathrm{E}_{2}$ for 1 week followed by a further 2 weeks of treatment in which the $E_{2}$ was combined with either TAM or fulvestrant. An additional group of mice were treated with $0.5 \mathrm{mg} \mathrm{E}_{2}$ only, whereas the negative control group received vehicle alone. Treatment with $0.5 \mathrm{mg} \mathrm{E}_{2}$ was sufficient to increase Ki67 expression in the population-risk, highrisk and All mutations groups (Figures $4 \mathrm{~A}, \mathrm{~B}$ and $\mathrm{C}$; $P<0.01$ by Mann-Whitney $U$-test compared to the appropriate untreated control for each risk group). Addition of TAM at a dose of $1 \mathrm{mg}$ mouse ${ }^{-1}$ day $^{-1}$ reduced expression of Ki67 in these three risk groups compared to $0.5 \mathrm{mg} \mathrm{E}_{2}$ alone $(P<0.05$ by Mann-Whitney $U$-test in each risk group). The percentage of Ki67-positive cells was also reduced by the addition of fulvestrant $\left(5 \mathrm{mg}\right.$ mouse ${ }^{-1}$ week $^{-1}$ ) in the population risk, increased $=$ risk and All Mutations groups compared to $0.5 \mathrm{mg} \mathrm{E}_{2}$ alone (Figure $4 \mathrm{~A}, \mathrm{~B}$ and $\mathrm{C} ; \mathrm{P}<0.05$ by Mann-Whitney $U$-test in each risk group). Both TAM and fulvestrant, when added to $0.5 \mathrm{mg} \mathrm{E}_{2}$, reduced the median 

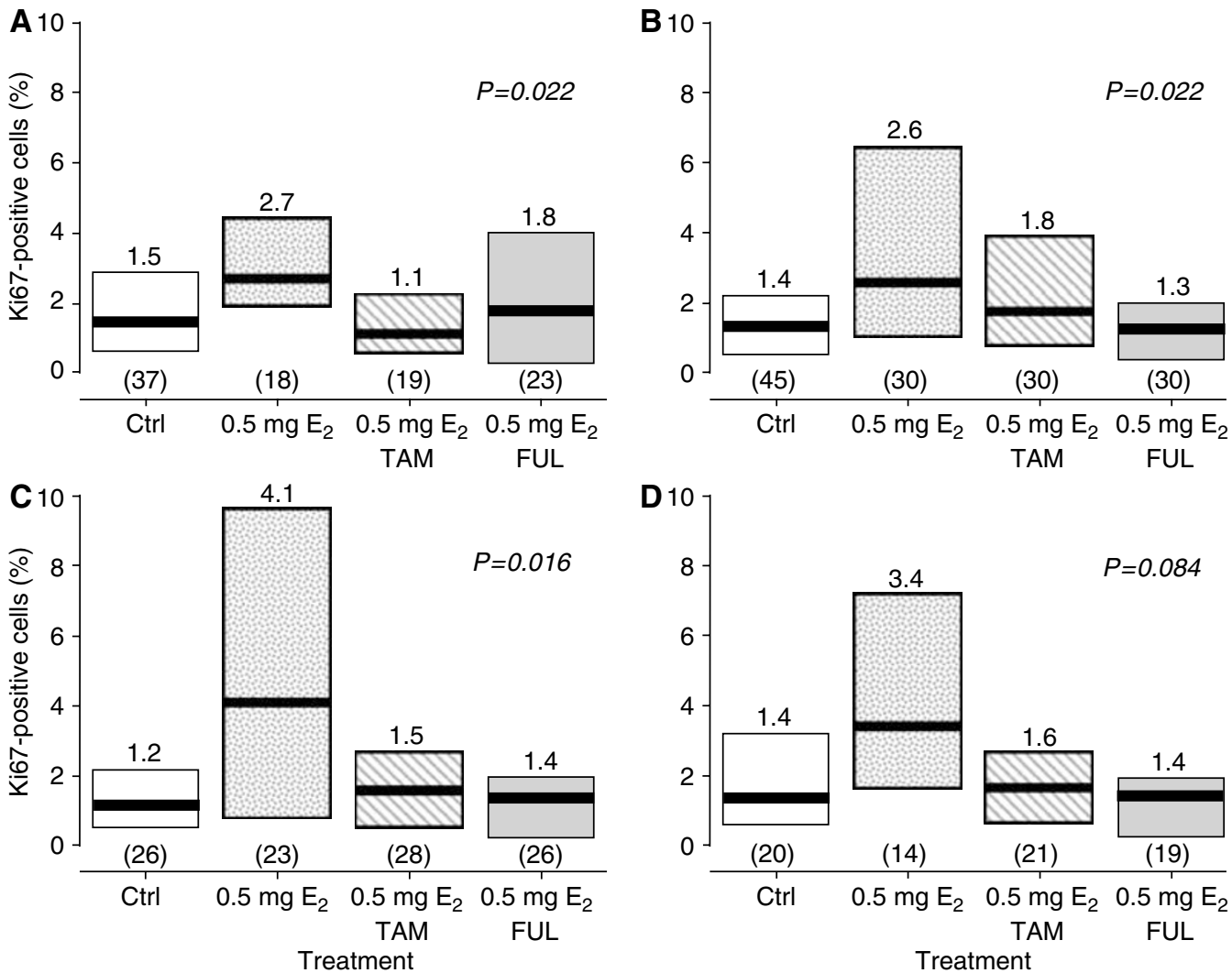

Figure 4 The proliferative activity of normal breast epithelium taken from women at population risk of breast cancer $(\mathbf{A})$, those at high risk $(\mathbf{B})$, those carrying BRCA I and BRCA2 mutations $(\mathbf{C})$ and BRCA I mutation carriers only (D) after implantation into athymic nude mice and treatment with 0.5 mg $E_{2}$ for I week followed by 2 weeks of $E_{2}$ combined with either TAM or fulvestrant. The thick horizontal lines indicate the medians as do the numbers on top of the columns indicating the IQRs. The numbers in parentheses are the numbers of samples available for analysis in each treatment group and the $P$-values indicate the significance of the differences across the treatment groups by the Kruskal-Wallis nonparametric analysis of variance. Ctrl=control; $0.5 \mathrm{mg}$ $E_{2}=$ treatment with $0.5 \mathrm{mg} E_{2}$-silastic pellets; TAM = tamoxifen $\left(1 \mathrm{mg}\right.$ mouse ${ }^{-1}$ day $\left.^{-1}\right) ; F U L=$ fulvestrant $\left(5 \mathrm{mg} \mathrm{mouse}^{-1}\right.$ week $\left.^{-1}\right)$.

percentages of Ki67-positive breast epithelial cells to the levels seen in untreated controls in the population-risk, increased-risk and all mutations groups (no significant difference when compared to controls by Mann-Whitney $U$-test in each risk group). Separate analysis of the tissue samples from women bearing BRCA1 mutations (Figure 4D) showed that the effects of $0.5 \mathrm{mg} E_{2}$ in the absence and presence of TAM or fulvestrant did not quite reach statistical significance $(P=0.084$ by Kruskal - Wallis test) although the pattern of changes reflected those seen in the other risk groups.

The ability of TAM and fulvestrant to reverse the effects of highdose ( $2 \mathrm{mg}) \mathrm{E}_{2}$ treatment on breast epithelial cell Ki67 expression was also investigated (data not shown). Both anti-oestrogens could reduce the effects of $\mathrm{E}_{2}$ on proliferation in all the risk groups but their effects were rather more variable presumably because the serum drug levels achieved with the above dosing schedules were not sufficient to overcome the high plasma $\mathrm{E}_{2}$ levels reached after treatment with the $2 \mathrm{mg} \mathrm{E} 2$ pellet.

\section{DISCUSSION}

The effects of heterozygous mutations in the BRCA1 or BRCA2 breast cancer-predisposing genes on the endocrine sensitivity of human breast epithelial cells are unknown. It is important to determine what these effects may be because of the increasing use of endocrine agents such as TAM for breast cancer prevention in $B R C A 1$ and BRCA2 mutation carriers. Although the BRCA1 and BRCA2 proteins play critical roles in DNA damage repair (Brodie and Deng, 2001; Deng and Brodie, 2001; Kerr and Ashworth, 2001), in vitro studies suggest that the BRCA1 gene product can also interact with and suppress the activity of the ER $\alpha$ (Fan et al, 1999; Fan et al, 2001). As $E_{2}$ is the major steroid mitogen for the human breast epithelium acting via the $\mathrm{ER} \alpha$, it might be predicted that $B R C A 1$ and, possibly, BRCA2 haploinsufficiency would result in an enhanced proliferative response to $E_{2}$. The present data show that this is not the case as proliferation of breast epithelium from mutation carriers in response to $\mathrm{E}_{2}$ treatment does not differ significantly from that of tissue from women at population risk of the disease. Secondly, it might be predicted that $B R C A 1$ and $B R C A 2$ haploinsufficiency would confer anti-oestrogen resistance to the breast epithelium. Again, we show that this is not the case as both the SERM TAM and the specific anti-oestrogen fulvestrant could reverse the effects of $\mathrm{E}_{2}$ on proliferation. Both antioestrogens also reversed the proliferative effects of $E_{2}$ in tissue from women at high risk of breast cancer because of their family history. These findings lead us to suggest that early intervention to antagonise the effects of $E_{2}$ or reduce serum $E_{2}$ levels would be effective for the prevention of breast cancer in BRCA1 or BRCA2 mutation carriers. As both the BRCA1 and BRCA2 proteins are involved in postreplicative DNA repair (Brodie and Deng, 2001; Deng and Brodie, 2001; Kerr and Ashworth, 2001), reducing the proliferative activity of the breast luminal epithelial cell population from which most tumours are derived should reduce the number of opportunities for replication errors to occur. The propagation of potentially transforming mutations might also be reduced.

Although there are no apparent alterations in the proliferative activity of the tissue from $B R C A 1$ and $B R C A 2$ mutation carriers, we have been able to detect a defect in the kinetics of PgR induction by $E_{2}$. As far as we are aware, this is one of the first reports of a 
biological phenotype associated with heterozygous mutations in the BRCA1 and BRCA2 genes, and complements the recent reports of an effect on PgR expression by Mote et al (2004). The delayed $\mathrm{PgR}$ response to $\mathrm{E}_{2}$ in the mutation carriers is paradoxical in the face of the in vitro evidence suggesting that the BRCA1 gene product is a repressor of both nuclear and nongenomic mechanisms of $\mathrm{ER} \alpha$ action (Fan et al, 1999, 2001; Razandi et al, 2004). However, some of these experiments used reporter constructs containing a consensus oestrogen response element (ERE) from the vitellogenin gene to examine the effects of the BRCA1 protein on $\mathrm{ER} \alpha$ transcriptional activity (Fan et al, 1999), whereas others have shown that overexpression of BRCA1 abrogates the effects of $\mathrm{E}_{2}$ on expression of the oestrogen-induced genes, pS2 and cathepsin D (Fan et al, 2001). The PgR gene promoter does not contain a complete ERE but it does have ERE half sites adjacent to those for Sp-1 (Petz and Nardulli, 2000), and it is possible that the BRCA1 protein has significantly different effects at this site in human breast epithelium in vivo. Alternatively, the differences in expression of PgR in response to $\mathrm{E}_{2}$ treatment may result from an alteration in the ratio of the A and B isoforms of the PR. Many commercially available antibodies used for PgR IHC fail to detect the $\mathrm{B}$ form of the receptor in formalin-fixed, paraffin-embedded tissues (Mote et al, 2001). The specificity of the antibody used in the present study is not known at present, but it is probable that it also does not detect PgRB in routinely processed tissue. Therefore, the apparent alteration in $\mathrm{PgR}$ induction following $\mathrm{E}_{2}$ treatment of tissue from women with $B R C A$ mutations may reflect an alteration in the PgRA to PgRB ratio such that PgRB expression is increased at the expense of PgRA. One way of confirming this would be to use more specific antibodies to determine the ratios of the two PgR isoforms in the breast epithelium from the mutation carriers compared to those from subjects at population risk of breast cancer. This approach has been used by Mote et al (2004) who have shown that not only is the ratio of PgRA to PgRB altered in favour of PgRA in normal breast tissue taken from $B R C A 1$ and $B R C A 2$ mutation carriers but also that expression of both isoforms is markedly reduced compared to tissue from normal-risk women. This suggests that the reduced levels of PgR expression seen in the mutation carriers in the present study is due to a reduction in both $\mathrm{PgR}$ isoforms. Finally, we have shown that luminal epithelial cells that proliferate in response to $\mathrm{E}_{2}$ do not contain the $\mathrm{ER} \alpha$, whereas $\mathrm{PgR}$ is expressed only in ER $\alpha$-positive cells (Clarke et al, 1997b). Clearly, BRCA1 would act as a coregulator of ER $\alpha$ activity only in cells that contain the receptor; therefore, we might expect BRCA1 to be involved directly in the control of PgR expression but not proliferation and this is supported by the present data. It will be important to determine exactly how the BRCA1 and BRCA2 gene products contribute to the control of $\mathrm{PgR}$ expression in the human breast epithelium. The effects of $\mathrm{E}_{2}$ on $\mathrm{PgR}$ expression in tissue from the high-risk group of women also appeared to be altered although the differences between this group and the population risk group just failed to reach significance. This may reflect the fact that many of the women in this risk group were given a probability of developing breast cancer of at least one in four based on their family history. Accordingly, one in four of these women could be carrying $B R C A 1$ and $B R C A 2$ mutations, whereas the others will be at population risk of the disease. This would dilute the alteration in the effects of $\mathrm{E}_{2}$ on $\mathrm{PgR}$ expression associated with $B R C A$ gene mutations in this group.

A potential criticism of our line of thinking could be that there is no haploinsufficient effect of a $B R C A 1$ or $B R C A 2$ mutation, and that anti-oestrogen treatment functions only as a secondary preventer of breast cancer. Given that primary prevention of breast cancer would have to take place at least 6 and possibly 10 years prior to a clinically apparent breast tumour being detected, none of the prevention trials and particularly not the NSABP trial (King et al, 2001) would have been powered to detect a primary preventive role. There is nonetheless evidence from BRCA1 mutation carriers that TAM may be effective in long-term prevention of second primary cancers and part of this is likely to be due to a primary preventive role. This is because the level of reduction seen would not be consistent with secondary prevention of what are mostly ERnegative tumours (Narod et al, 2000; Metcalfe et al, 2004). That primary prevention of breast cancer in BRCA carriers occurs by reducing oestrogen stimulation of the breast is now beyond dispute. Oophorectomy prior to the menopause substantially reduces the risks of breast cancer (Rebbeck et al, 2001, 2002). Even though $B R C A 1$ cancers are thought to derive from basal cells that are ER negative, these cells are still under the influence of neighbouring ER-positive epithelial cells. Reducing the growth-inducing signals of these cells will potentially reduce proliferation of the basal cells and reduce the chances of introducing mutations during cell division by naturally occurring replication error. Even if there is no heterozygous effect on the cell of carrying a $B R C A$ mutation, antioestrogen treatment is still likely to be effective in primary prevention by this mechanism. Yet, there may well be a haploinsufficient effect. We have shown that there does appear to be a difference between BRCA1-mutated epithelial cells and controls. Moreover, Kote-Jarai et al (2004) have shown that fibroblasts from $B R C A 1$ mutation carriers can be distinguished from controls in terms of their response to radiation damage in microarray analysis. The elusive haploinsufficient effect and a functional assay for the heterozygous state may not be too far away.

In summary, we have shown that $\mathrm{E}_{2}$-stimulated proliferation in breast epithelium taken from women bearing heterozygous mutations in the BRCA1 and BRCA2 genes can be reversed by both a SERM (TAM) and an anti-oestrogen (fulvestrant) that is without agonist effects. We have also shown that altered expression of $\mathrm{PgR}$ is a phenotype associated with mutations in the BRCA1 and BRCA2 genes. We conclude that early antioestrogen treatment should be effective for the prevention of breast cancer in high-risk women.

\section{ACKNOWLEDGEMENTS}

This study was funded by the Christie Hospital Research Endowment Fund and by AstraZeneca Pharmaceuticals. We are grateful to Dr Alan Wakeling of Astrazeneca for supplying the fulvestrant used in this study and to Dr John Coyne (South Manchester University Hospitals Trust) for his assistance with the histological examination of the specimens used.

\section{REFERENCES}

Brodie SG, Deng CX (2001) BRCA1-associated tumorigenesis: what have we learned from knockout mice? Trends Genet 17: S18-S22

Brown MA, Nicolai H, Howe K, Katagiri T, Lalani el N, Simpson KJ, Manning NW, Deans A, Chen P, Khanna KK, Wati MR, Griffiths BL, Xu CF, Stamp GW, Solomon E (2002) Expression of a truncated Brcal protein delays lactational mammary development in transgenic mice. Transg Res 11: $467-478$
Chodosh LA (1998) Expression of BRCA1 and BRCA2 in normal and neoplastic cells. J Mammary Gland Biol Neoplasia 3: 389-402

Clarke RB, Howell A, Anderson E (1997a) Estrogen sensitivity of normal human breast tissue in vivo and implanted into athymic nude mice: analysis of the relationship between estrogen-induced proliferation and progesterone receptor expression. Breast Cancer Res Treat 45: $121-133$ 
Clarke RB, Howell A, Potten CS, Anderson E (1997b) Dissociation between steroid receptor expression and cell proliferation in the human breast. Cancer Res 57: 4987-4991

Cuzick J, Powles T, Veronesi U, Forbes J, Edwards R, Ashley S, Boyle P (2003) Overview of the main outcomes in breast-cancer prevention trials. Lancet 361: $296-300$

Deng CX, Brodie SG (2001) Knockout mouse models and mammary tumorigenesis. Semin Cancer Biol 11: 387-394

Deng CX, Scott F (2000) Role of the tumor suppressor gene Brcal in genetic stability and mammary gland tumor formation. Oncogene 19: 1059-1064

Fan S, Ma YX, Wang C, Yuan RQ, Meng Q, Wang JA, Erdos M, Goldberg ID, Webb P, Kushner PJ, Pestell RG, Rosen EM (2001) Role of direct interaction in BRCA1 inhibition of estrogen receptor activity. Oncogene 20: $77-87$

Fan S, Wang J, Yuan R, Ma Y, Meng Q, Erdos MR, Pestell RG, Yuan F, Auborn KJ, Goldberg ID, Rosen EM (1999) BRCA1 inhibition of estrogen receptor signaling in transfected cells. Science 284: 1354-1356

Fisher B, Costantino JP, Wickerham DL, Redmond CK, Kavanah M, Cronin WM, Vogel V, Robidoux A, Dimitrov N, Atkins J, Daly M, Wieand S, Tan-Chiu E, Ford L, Wolmark N (1998) Tamoxifen for prevention of breast cancer: report of the National Surgical Adjuvant Breast and Bowel Project P-1 Study. J Natl Cancer Inst 90: 1371 - 1388

Hopper JL (2001) Genetic epidemiology of female breast cancer. Semin Cancer Biol 11: $367-374$

Kerr P, Ashworth A (2001) New complexities for BRCA1 and BRCA2. Curr Biol 11: R668 - R676

King MC, Wieand S, Hale K, Lee M, Walsh T, Owens K, Tait J, Ford L, Dunn BK, Costantino J, Wickerham L, Wolmark N, Fisher B, National Surgical Adjuvant Breast and Bowel Project (2001) Tamoxifen and breast cancer incidence among women with inherited mutation in BRCA1 and BRCA2: National Surgical Adjuvant Breast and Bowel Project (NSABP-P1) Breast Cancer Prevention Trial. JAMA 286(18): $2251-2256$

Kote-Jarai Z, Williams RD, Cattini N, Copeland M, Giddings I, Wooster R, tePoele RH, Workman P, Gusterson B, Peacock J, Gui G, Campbell C, Eeles R (2004) Gene expression profiling after radiation-induced DNA damage is strongly predictive of BRCA1 mutation carrier status. Clin Cancer Res 10: $958-963$

Laidlaw IJ, Clarke RB, Howell A, Owen AW, Potten CS, Anderson E (1995) The proliferation of normal human breast tissue implanted into athymic nude mice is stimulated by estrogen but not progesterone. Endocrinology 136: $164-171$

Lakhani SR (1999) The pathology of familial breast cancer: morphological aspects. Breast Cancer Res 1: 31 - 35

Lakhani SR, Van De Vijver MJ, Jacquemier J, Anderson TJ, Osin PP, McGuffog L, Easton DF (2002) The pathology of familial breast cancer: predictive value of immunohistochemical markers estrogen receptor, progesterone receptor, HER-2, and p53 in patients with mutations in BRCA1 and BRCA2. J Clin Oncol 20: 2310-2318

Metcalfe K, Lynch HT, Ghadirian P, Tung N, Olivotto I, Warner E, Olopade OI, Eisen A, Weber B, McLennan J, Sun P, Foulkes WD, Narod SA (2004) Contralateral breast cancer in BRCA1 and BRCA2 mutation carriers. $J$ Clin Oncol 22: 2328-2335

Mote PA, Johnston JF, Manninen T, Tuohimaa P, Clarke CL (2001) Detection of progesterone receptor forms $\mathrm{A}$ and $\mathrm{B}$ by immunohistochemical analysis. J Clin Pathol 54: 624-630

Mote PA, Leary JA, Avery KA, Sandelin K, Chenevix-Trench G, Kirk JA, Clarke CL (2004) Germ-line mutations in BRCA1 or BRCA2 in the normal breast are associated with altered expression of estrogenresponsive proteins and the predominance of progesterone receptor A. Genes Chromosomes Cancer 39: 236-248

Narod SA, Brunet JS, Ghadirian P, Robson M, Heimdal K, Neuhausen SL, Stoppa-Lyonnet D, Lerman C, Pasini B, de los Rios P, Weber B, Lynch H (2000) Tamoxifen and risk of contralateral breast cancer in BRCA1 and BRCA2 mutation carriers: a case-control study. Hereditary Breast Cancer Clinical Study Group. Lancet 356: 1876 - 1881

Osborne CK, Coronado-Heinsohn EB, Hilsenbeck SG, McCue BL, Wakeling AE, McClelland RA, Manning DL, Nicholson RI (1995) Comparison of the effects of a pure steroidal antiestrogen with those of tamoxifen in a model of human breast cancer. J Natl Cancer Inst 87: 746-750

Petz LN, Nardulli AM (2000) Sp1 binding sites and an estrogen response element half-site are involved in regulation of the human progesterone receptor A promoter. Mol Endocrinol 14: $972-985$

Razandi M, Pedram A, Rosen EM, Levin ER (2004) BRCA1 inhibits membrane estrogen and growth factor receptor signaling to cell proliferation in breast cancer. Mol Cell Biol 24: 5900-5913

Rebbeck TR (2002) Inherited predisposition and breast cancer: modifiers of BRCA1/2-associated breast cancer risk. Environ Mol Mutagen 39: $228-234$

Rebbeck TR, Lynch HT, Neuhausen SL, Narod SA, Van't Veer L, Garber JE Evans G, Isaacs C, Daly MB, Matloff E, Olopade OI, Weber BL (2002) Prophylactic oophorectomy in carriers of BRCA1 or BRCA2 mutations. $N$ Engl J Med 346: 1616-1622

Rebbeck TR, Wang Y, Kantoff PW, Krithivas K, Neuhausen SL, Godwin AK, Daly MB, Narod SA, Brunet JS, Vesprini D, Garber JE, Lynch HT, Weber BL, Brown M (2001) Modification of BRCA1- and BRCA2-associated breast cancer risk by AIB1 genotype and reproductive history. Cancer Res 61: $5420-5424$

Venkitaraman AR (2001) Functions of BRCA1 and BRCA2 in the biological response to DNA damage. J Cell Sci 114: $3591-3598$

Xu X, Wagner KU, Larson D, Weaver Z, Li C, Ried T, Hennighausen L, Wynshaw-Boris A, Deng CX (1999) Conditional mutation of Brcal in mammary epithelial cells results in blunted ductal morphogenesis and tumour formation. Nat Genet 22: $37-43$ 